\title{
Characterization of the coupling activity for the binding of inter- $\alpha$-trypsin inhibitor to hyaluronan in human and bovine follicular fluid
}

\author{
L. Ødum ${ }^{1}$, C. Yding Andersen ${ }^{2}$ and T. E. Jessen ${ }^{3}$ \\ ${ }^{1}$ Department of Clinical Biochemistry, Roskilde University Hospital, 7-13 Kogevej, DK-4000 \\ Roskilde, Denmark; ${ }^{2}$ Laboratory of Reproductive Biology, Section 5712, University Hospital \\ of Copenhagen, DK-2100 Copenhagen, Denmark; and ${ }^{3}$ Department of Clinical \\ Biochemistry, Holbæk, Sygehus Vestsjælland, DK-4300 Holbæk, Denmark
}

The plasma proteinase inter- $\alpha$-trypsin inhibitor is necessary for normal expansion of the cumulus-oocyte complex (COC) and lack of inter- $\alpha$-trypsin inhibitor results in severe infertility. After diffusion from the circulation into the follicles, inter- $\alpha$-trypsin inhibitor is incorporated into the extracellular hyaluronan network of the expanding COC. However, mixing isolated inter- $\alpha$-trypsin inhibitor with hyaluronan in vitro does not result in coupling to hyaluronan. Other components must be present. A recently developed electrophoretic technique by which hyaluronanbound inter- $\alpha$-trypsin inhibitor is immobilized was used to demonstrate coupling activity in human and bovine follicular fluid that is necessary for the formation of a firm binding between inter- $\alpha$-trypsin inhibitor heavy chains and hyaluronan, as observed in vivo. No coupling activity could be detected in human serum. Coupling occurred only in the presence of follicular fluid. The coupling activity of

\section{Introduction}

Normal development of the cumulus-oocyte complex (COC), which undergoes a profound expansion before ovulation in response to the mid-cycle surge of gonadotrophins, is important for normal ovulation and collection of the COC by the oviduct (Salustri et al., 1989; Hess et al., 1999; Lam et al., 2000). FSH stimulates hyaluronan production in follicular cells (Eppig, 1979) and the ovulatory surge induces an increase in the permeability of the blood-follicle barrier leading to an influx of plasma-derived proteins including inter- $\alpha$-trypsin inhibitor (ITI) (Powers et al., 1995; Hess et al., 1998). ITI is connected to hyaluronan (Chen et al., 1992, 1994; Jessen et al., 1994) and the complex formed stabilizes the extracellular matrix (Chen et al., 1992, 1994). Studies in mice have shown that ITI is essential for normal reproduction, as female mice lacking ITI suffer from severe infertility; however, infertility can be reversed by injection of ITI (Sato et al., 2001; Zhuo et al., 2001).

Email: rslaod@ra.dk follicular fluid was irreversibly destroyed by heat treatment, lowering of $\mathrm{pH}$ or tryptic digestion, indicating that the coupling activity is associated with a protein. Calcium ions are essential for the coupling reaction. The binding reaction in vitro using intact inter- $\alpha$-trypsin inhibitor is slow and occurs over $24 \mathrm{~h}$. The early-formed complexes between inter- $\alpha$-trypsin inhibitor and hyaluronan contain small amounts of bikunin, whereas the end product contains heavy chains and essentially no bikunin. The heavy chains released from inter- $\alpha$-trypsin inhibitor by $\mathrm{NaOH}$ treatment bound immediately to hyaluronan, indicating that the dissociation of heavy chains from inter- $\alpha$-trypsin inhibitor is the rate-limiting step. In conclusion, at least four components are essential for the covalent binding of heavy chains to hyaluronan: inter- $\alpha$ trypsin inhibitor and calcium from plasma, hyaluronan and one or more proteins found in follicular fluid.

Human ITI is synthesized by the liver and consists of three different polypeptide chains: bikunin, heavy chain 1 and heavy chain 2 (Ødum, 1990; Salier et al., 1996; Fries and Blom, 2000). Bikunin, a Kunitz type proteinase inhibitor, is covalently linked to both of the heavy chains via a chondroitin sulphate bridge (Jessen et al., 1988; Enghild et al., 1989).

A complex between hyaluronan and the two heavy chains is generated (Huang et al., 1993) similar to the complex detected in vivo in follicular fluid and synovial fluid (Jessen et al., 1994). Consequently, bikunin is detached just before, during or after the coupling of ITI to hyaluronan.

Oocytes in mice lacking bikunin-ITI complexes sometimes lack zona pellucida (Sato et al., 2001). As the zona pellucida contains bikunin (Ødum and Nielsen, 1997), bikunin might be important for normal zona pellucida development. Bikunin is a proteinase inhibitor of plasmin among others, but several functions have been ascribed to bikunin as reviewed by Fries and Blom (2000).

Tumour necrosis factor-stimulated gene 6 (TSG-6) can form a stable complex with ITI consisting of TSG-6, heavy 
chain 2 (HC2) and bikunin (Wisniewski et al., 1994). TSG-6, ITI and hyaluronan co-localize in mouse cumulus extracellular matrix (Carrette et al., 2001). A $120 \mathrm{kDa}$ complex between TSG- 6 and apparently heavy chain 1 or heavy chain 2 has been extracted from mouse COCs. Furthermore, the complex seems to bind hyaluronan as it is released from COCs only by hyaluronidase treatment (Mukhopadhyay et al., 2001). The binding of TSG-6 to ITI appears to increase the plasmin inhibitory activity of ITI (Wisniewski et al., 1996).

The heavy chain-hyaluronan complexes found in vivo are connected covalently by an ester bond (Zhao et al., 1995). In the present study, mixing of serum including ITI and hyaluronan caused no stable coupling of ITI to hyaluronan. As cultured granulosa cells produce a factor mediating the coupling (Chen et al., 1996), it was assumed that the stabilization of the extracellular matrix induced by ITI depends on more locally produced compounds in the follicle than on hyaluronan.

Development of the separation electrophoresis (Jessen et al., 1994) made it possible to test for 'coupling activity' in unpurified material. This method was used in the present study to determine whether a protein in human and bovine follicular fluid was necessary for the firm coupling of ITI to hyaluronan. Furthermore, investigation of the reaction conditions demonstrated that calcium ions are essential for the coupling reaction and that free heavy chains participate in the coupling reaction at a faster rate than intact ITI. Finally, the coupling activity has been quantified in human follicular fluid collected before or after the normal LH surge or hCG administration.

\section{Materials and Methods}

\section{Reagents and chemicals}

Ovine testicular hyaluronidase (EC 3.2.1.35, spec. activity: 49130 national forumulatory (NF) units (as defined in United States Pharmacopeia) per mg protein (art. no. 38594) and human umbilical cord hyaluronic acid (art. no. 385902) were obtained from Calbiochem (Novabiochem Corporation, Darmstadt). Rabbit anti-human ITI immunoglobulin directed against all peptides of ITI (that is, bikunin, heavy chain 1 and heavy chain 2) was obtained from Dako A/S (Copenhagen; code A 301) (Jessen et al., 1994). Trypsin from bovine pancreas (activity: 12700 benzoyl-L-arginine ethyl ester (BAEE) units per mg, T-8253) (one BAEE unit $=\mathrm{A}_{253}$ of 0.001 pr. min with BAEE as substrate at $\mathrm{pH} 7.6$ at $\left.25^{\circ} \mathrm{C}\right)$, and proteinase inhibitors: phenylmethylsulphonyl fluoride (PMSF), p-chloromercuribenzoic acid (PCMB), 1,10-phenanthroline monohydrate, 6-amino-hexanoic acid (EACA), benzamidine hydrochloride and soybean trypsin inhibitor (activity: $1.6 \mathrm{mg}$ will inhibit $1.6 \mathrm{mg}$ trypsin, T-9003) were obtained from Sigma (Aldrich Chemie Gmbh, Steinheim). Agarose LSL 4000 was obtained from FMC BioProducts (Rockland, ME). Hyaluronidase-digested bikunin was prepared by incubating partly purified bikunin (200 $\mathrm{mg} \mathrm{l}^{-1}$ ) (Ødum and Nielsen, 1997) with ovine testicular hyaluronidase $\left(2000 \mathrm{U} \mathrm{ml}^{-1}\right)$. ITI was purified from serum using the method described by Jochum and Bittner (1983) and appeared on SDS-PAGE as a single band of $240 \mathrm{kDa}$ (not shown). The metal ion chelators EDTA and EGTA as well as all other reagents and chemicals were of analytical grade.

\section{Sample collection}

Human follicular fluid that represented four different types of preovulatory follicular fluid was obtained as described by Andersen et al. (1999). In brief, in group 1, follicles were aspirated from women $(n=3)$ just before the induction of ovulation by the administration of hCG (that is, $36 \mathrm{~h}$ before expected ovulation). When the largest follicle was $\geqslant 17 \mathrm{~mm}$ in diameter, all follicles $\geqslant 10 \mathrm{~mm}$ in diameter were aspirated on the following day, except for the two or three largest follicles. After sampling, the couple were advised to have intercourse $24-48 \mathrm{~h}$ after the injection of hCG. In group 2, women $(n=9)$ received ovarian stimulation according to the flare-up protocol, including GnRH agonist administration in combination with exogenous human menopausal gonadotrophin (Andersen, 1993). Ovulation was induced with hCG (10000 iu) when at least two follicles measured $\geqslant 17 \mathrm{~mm}$ in diameter and oocyte retrieval was performed $36 \mathrm{~h}$ later. Group 3 consisted of women who had normal menstrual cycles with a normal endogenous mid-cycle of gonadotrophins inducing ovulation. Each woman $(n=11)$ developed one follicle and ovulation was predicted by measurement of $\mathrm{LH}$ in urine. Group 4 consisted of women $(n=9)$ with natural menstrual cycles in whom ovulation was induced with hCG (10000 iu) when the preovulatory follicle measured $\geqslant 18 \mathrm{~mm}$ in diameter. Aspiration of the oocyte was performed $36 \mathrm{~h}$ after injection of hCG. In all cases, follicular fluid was collected into a syringe by manual suction ensuring no contamination of flushing fluid. The use of human follicular fluid for research purposes was approved by the Ethical Committee for counties of Copenhagen and Frederiksberg, and the women gave their informed consent after having received information orally and in writing.

Pooled bovine follicular fluids were produced from ovaries as described by Avery et al. (1998).

\section{Testing for coupling activity}

One volume of bovine follicular fluid was mixed with one volume of buffer $\left(10 \mathrm{mmol}\right.$ phosphate buffer $\mathrm{I}^{-1}$, $\mathrm{pH} 7.4$, with or without $4 \mathrm{mg} \mathrm{ml}^{-1}$ hyaluronan) and with two volumes of normal human serum (Fig. 1). The solutions were then incubated at $37^{\circ} \mathrm{C}$. Aliquots were withdrawn $(0$, 1,3 and $24 \mathrm{~h}$ ) and stored at $-20^{\circ} \mathrm{C}$ until analysis.

Experiments were performed by mixing the following components: (i) follicular fluid: one volume (human or bovine) to be tested for coupling activity; (ii) buffer: one volume of $45.0 \mathrm{mmol}$ Tris- $\mathrm{HCl} \mathrm{I-1,} \mathrm{pH} 7.4,4.5 \mathrm{mmol}$ $\mathrm{CaCl}_{2} \mathrm{I}^{-1}, 150.0 \mathrm{mmol} \mathrm{NaCl} \mathrm{I-1}, \pm 4.5 \mathrm{mg}$ hyaluronan $\mathrm{ml}^{-1}$, with or without inhibitors; (iii) ITI source: one volume of 
Table 1. Components required for formation of heavy chain-hyaluronan complexes

\begin{tabular}{|c|c|c|c|c|c|}
\hline \multirow[b]{2}{*}{ Experiment } & \multirow[b]{2}{*}{ Component } & \multicolumn{4}{|c|}{$\begin{array}{l}\text { Heavy chains }\left(\mathrm{mU} \mathrm{ml}^{-1}\right) \text { bound to } \\
\text { hyaluronana after: }\end{array}$} \\
\hline & & $\mathrm{Oh}$ & $3 \mathrm{~h}$ & $24 \mathrm{~h}$ & $24 h-0 h^{b}$ \\
\hline 1 & Hyaluronan + serum & 0 & 0 & 0 & 0 \\
\hline 2 & Hyaluronan + ITI & 0 & 0 & 0 & 0 \\
\hline 3 & Follicular fluid (human) + ITI & 24 & 19 & 17 & 0 \\
\hline 4 & Follicular fluid (human) + hyaluronan & 53 & 79 & 57 & 0 \\
\hline 5 & Follicular fluid (human) + ITI + hyaluronan & 59 & 79 & 160 & 101 \\
\hline 6 & Follicular fluid (human) + serum + hyaluronan & 63 & 92 & 140 & 77 \\
\hline 7 & Follicular fluid (bovine) + serum + hyaluronan & 11 & 83 & 98 & 87 \\
\hline 8 & Follicular fluid (bovine) + serum $^{\mathrm{c}}+$ hyaluronan & 84 & 84 & 87 & 3 \\
\hline 9 & Follicular fluid (human) + heavy chain ${ }^{d}+$ hyaluronan & 145 & 152 & 148 & 0 \\
\hline 10 & Follicular fluid (trypsine) + serum + hyaluronan & 0 & 0 & 21 & 21 \\
\hline
\end{tabular}

${ }^{a}$ Coupling activity is detected by an increasing concentration of heavy chain complexes after 3 and $24 \mathrm{~h}$.

${ }^{b}$ The increase in hyaluronan-bound heavy chains during the first $24 \mathrm{~h}$ is shown, that is, the value after $24 \mathrm{~h}$ minus the value at $0 \mathrm{~h}\left(\mathrm{mU} \mathrm{ml}^{-1}\right.$ day $\left.^{-1}\right)$.

${ }^{\mathrm{C}}$ Normal human serum treated with $75 \mathrm{mmol} \mathrm{NaOH} \mathrm{I}^{-1}$ to release the heavy chains of inter-alpha-trypsin inhibitor (ITI).

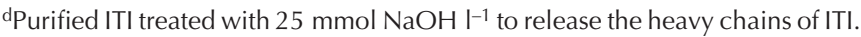

eBovine follicular fluid pretreated with trypsin.

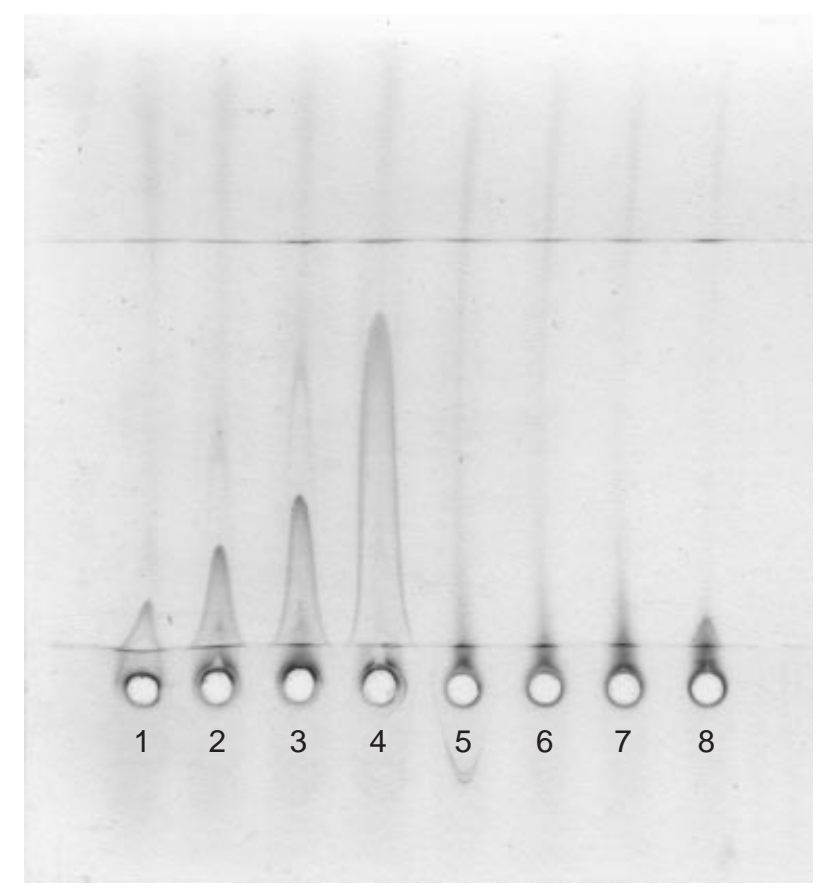

Fig. 1. Occurrence of coupling activity in bovine follicular fluid. Heavy chain-hyaluronan complexes were demonstrated by the two-step electrophoresis in which hyaluronan and hyaluronanbound proteins are retained in the electrophoretic wells. After removal of unbound proteins, hyaluronan-bound proteins were released by enzymatic degradation of hyaluronan. Lanes 1-4: mixture of bovine follicular fluid, hyaluronan and serum incubated for $0,1,3$ and $24 \mathrm{~h}$, respectively; lanes 5-8: mixture of bovine follicular fluid and serum without hyaluronan incubated for $0,1,3$ and $24 \mathrm{~h}$, respectively. normal human serum (ITI concentration $=1 \mathrm{U} \mathrm{ml}^{-1}$ ) or purified ITI (1.5 $\left.\mathrm{U} \mathrm{ml}^{-1}\right)$ (Table 1, Figs 2 and 3). The mixtures were incubated at $37^{\circ} \mathrm{C}$. Aliquots were withdrawn $\left(0,3\right.$ and $24 \mathrm{~h}$ ) and $1.5 \mathrm{~mol} \mathrm{NaCl}{ }^{-1}$ (one-third of the withdrawn volume) was added before storing at $-20^{\circ} \mathrm{C}$. In some experiments, one (or two) component was replaced with saline as shown (Table 1). The amount of heavy chains bound to hyaluronan was determined as described below.

One volume of bovine follicular fluid was mixed with one volume of 500 mmol phosphate buffer $\mathrm{I}^{-1}$, $\mathrm{pH} 7.4$ (with

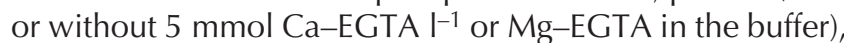
2.5 volumes of normal human serum and one volume of hyaluronan ( $5 \mathrm{mg} \mathrm{ml}^{-1}$ in physiological saline) (Fig. 4). The solutions were incubated at $37^{\circ} \mathrm{C}$. Aliquots were withdrawn at 0,2 and $4 \mathrm{~h}$, and stored at $-20^{\circ} \mathrm{C}$ until analysis. Samples were centrifuged at $10000 \mathrm{~g}$ for $10 \mathrm{~min}$ at $4^{\circ} \mathrm{C}$ just before electrophoresis.

Qualitative experiments (Figs 1-4) were performed several times. The quantitative results (Table 1 ) represent one experiment, but the overall conclusions have been confirmed by similar experiments using alternative incubation periods. The quantitations of coupling activity in follicular fluid from women with different hormone status were all determined in duplicate and the mean value was used (Table 2).

\section{Quantitation of hyaluronan-bound ITI polypeptides}

The quantitation of hyaluronan-bound (immobilized) heavy chains was performed by two-step electrophoresis (Jessen et al., 1994; Ødum et al., 2001). In principle, heavy chains bound to hyaluronan are retained in the application 


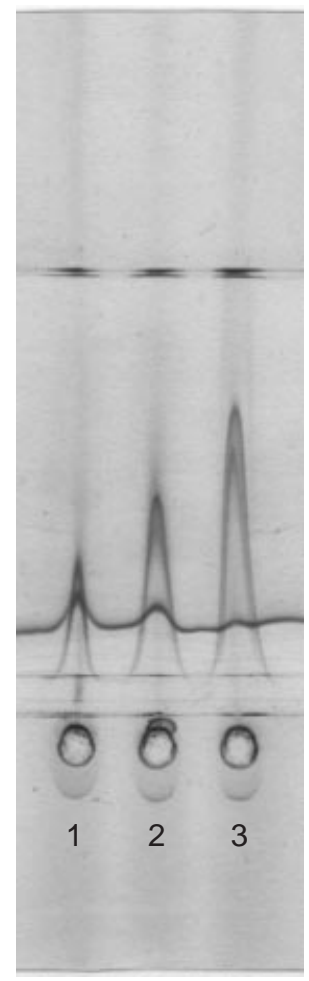

Fig. 2. Bikunin content of hyaluronan inter-alpha-trypsin inhibitor (ITI) complexes. A combination of bovine follicular fluid, serum and hyaluronan was incubated for 0 (lane 1), 3 (lane 2) and 24 (lane 3$) \mathrm{h}$ and tested electrophoretically with $2.5 \mu \mathrm{l}$ purified bikunin $\left(200 \mathrm{mg} \mathrm{l}^{-1}\right)$ included in a $3 \mathrm{~mm}$ narrow intermediate gel giving a line that crosses the rockets. Upward deflections are due to bikunin released after digestion of hyaluronan in the sample wells.

well during removal of unbound proteins by electrophoresis. The retained hyaluronan is then degraded and the released hyaluronan-bound proteins are detected by electrophoresis into an antibody containing gel. In step 1, separation electrophoresis of $10 \mu \mathrm{l}$ samples was carried out at $10 \mathrm{~V} \mathrm{~cm}^{-1}$ for $60 \mathrm{~min}$. After electrophoresis, sample wells were treated with testis hyaluronidase $(50 \mathrm{U}$ per well) for detection of hyaluronan-bound protein. In step 2, after digestion of hyaluronan in sample wells, the gel at the anodic side of the wells containing the anodic migrating proteins of the first run was replaced by anti-ITI gel $\left(1.2 \mu \mathrm{cm}^{-2}\right)$. Electroimmunoassay of the ITI polypeptides released by hyaluronidase treatment was run overnight at $2.5 \mathrm{~V} \mathrm{~cm}^{-1}$ into the anti-ITI gel (Axelsen and Bock, 1983).

For the digestion of hyaluronan, the use of hyaluronidase from ovine testes was preferred, because of its ability to degrade both hyaluronan and the chondroitin sulphate bridge of ITI. One arbitrary unit of heavy chain was defined as the total amount of heavy chain in $1 \mathrm{ml}$ normal human serum.

It is important to change the electrophoresis buffer before each run to avoid buffer-ion exhaustion and thereby to improve precision. The intra-assay coefficient of variation was $16 \%$ for the determination of hyaluronan-bound ITI.

\section{Coupling activity}

The coupling activity was expressed as the concentration of immobilized heavy chains formed during incubation for $1 \mathrm{~h}\left(\mathrm{mU} \mathrm{ml} \mathrm{m}^{-1} \mathrm{~h}^{-1}\right)$ and was determined as the mean increase in rocket height during the first $3 \mathrm{~h}$ of the incubation period, in which the substrates (ITI and hyaluronan) were in excess.

\section{$\mathrm{NaOH}$ degradation of ITI}

Purified ITI in saline was added to a final concentration of $25 \mathrm{mmol} \mathrm{NaOH} \mathrm{I}{ }^{-1}$, incubated for $30 \mathrm{~min}$ at $25^{\circ} \mathrm{C}$ and finally neutralized by acetic acid as described by Zhao et al. (1995) to release the two heavy chains of ITI from the chondroitin sulphate bridge. The concentration of $\mathrm{NaOH}$ was increased to $75 \mathrm{mmol} \mathrm{I}^{-1}$ to detach heavy chains from ITI in serum.

\section{Tryptic digestion of coupling factor}

Bovine follicular fluid $(1000 \mu \mathrm{l})$ was mixed with $100 \mu \mathrm{l}$ phosphate buffer (50 mmol $\mathrm{I}^{-1}, \mathrm{pH}$ 8.0) containing $10 \mathrm{mg}$ trypsin $\mathrm{ml}^{-1}$. After incubation at $37^{\circ} \mathrm{C}$ for $6 \mathrm{~h}, 100 \mu \mathrm{l}$ soybean trypsin inhibitor (10 $\mathrm{mg} \mathrm{m}^{-1}$ in phosphate buffer) was added. Finally, coupling activity was tested as described above.

\section{Inhibitors}

Coupling assays were performed as described above: (i) $100 \mu$ l bovine follicular fluid; (ii) $100 \mu$ l buffer with hyaluronan and inhibitors; and (iii) $100 \mu$ l human serum were incubated at $37^{\circ} \mathrm{C}$, and aliquots were withdrawn after 0,2 and $4 \mathrm{~h}$. Concentrations of inhibitors during the coupling reaction were $1.5 \mathrm{mmol} \mathrm{PMSF} \mathrm{I}^{-1}, 1.0 \mathrm{mmol}$ PCMB I-1, $1.0 \mathrm{mmol}$ 1,10-phenanthroline $\mathrm{I}^{-1}, 10.0 \mathrm{mmol}$ benzamidine $\mathrm{I}^{-1}, 25.0 \mathrm{mmol}$ EACA $\mathrm{I}^{-1}$ and $10.0 \mathrm{mmol}$

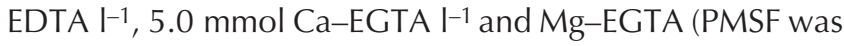
added directly into the mixture dissolved in isopropanol).

\section{Measurement of steroids}

Progesterone and oestradiol were monitored using a commercially available direct radioimmunoassay kit (Orion, Turku). The interassay coefficient of variation was $6-8 \%$ and results were considered valid only when two internal standards provided by the manufacturer were in the given range. Samples were diluted $1: 500$ or $1: 1000$ in steroid-free serum so that values were within the range of the standard curve.

\section{Statistical analysis}

As the material consisted of four groups of women who received different treatments and from whom one to four follicular fluid samples were tested, a random effect-multilevel model was used to compare the effects of ovarian 


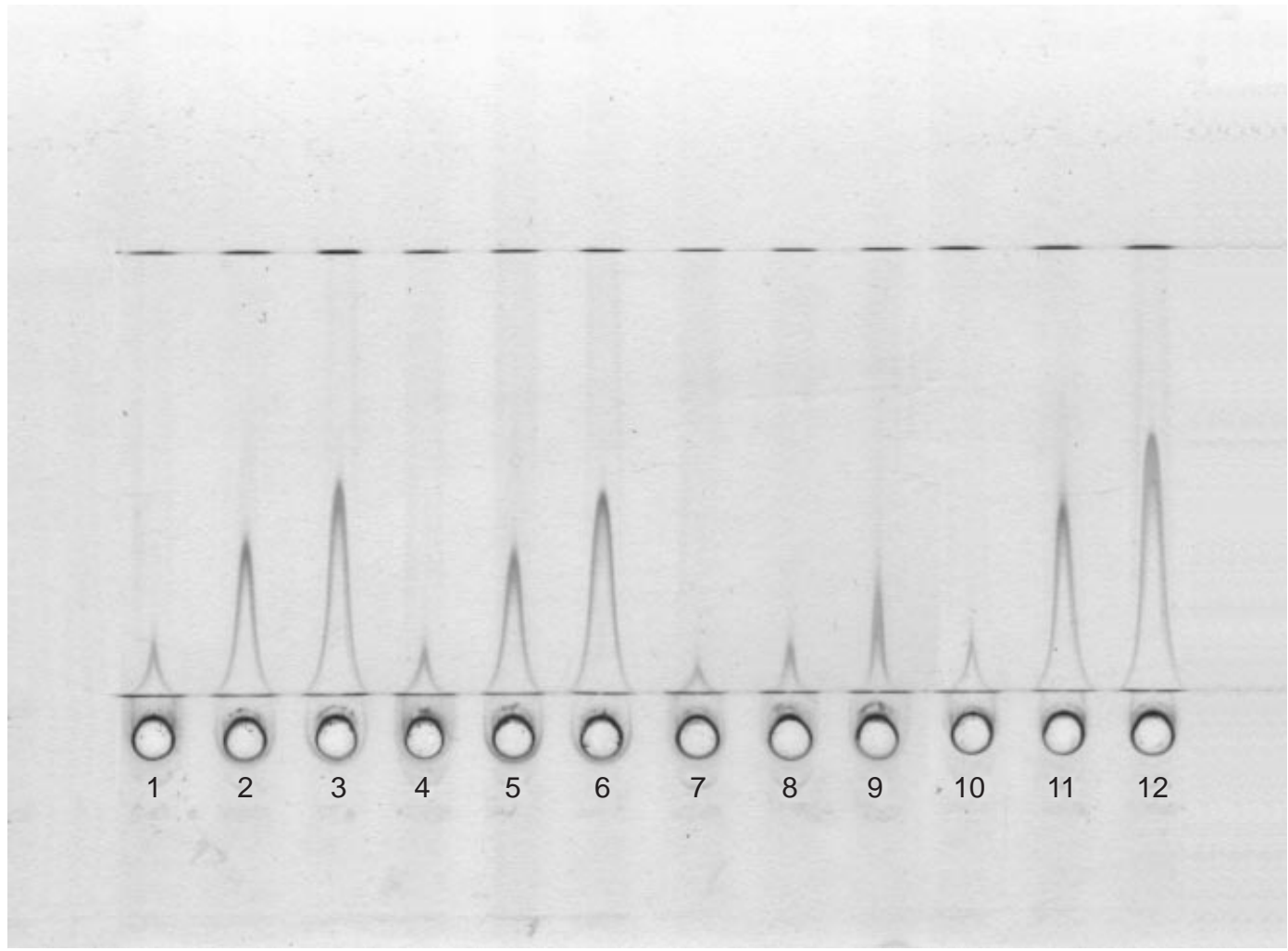

Fig. 3. Coupling activity is inhibited by EDTA. Combinations of bovine follicular fluid, serum and hyaluronan were incubated for 0 (lanes 1, 4, 7 and 10), 3 (lanes 2, 5, 8 and 11) and $24 \mathrm{~h}$ (lanes 3, 6, 9 and 12). Lanes 1-3: control; lanes 4-6: addition of proteinase inhibitors (phenylmethylsulphonyl fluoride (PMSF), benzamidine, 1,10-phenanthroline, p-chloromercuribenzoate and 6-amino-hexanoic acid (EACA) without EDTA; lanes 7-9: addition of proteinase inhibitors plus EDTA; and lanes 10-12: EDTA was added after incubation (without inhibitors) and formation of complexes.

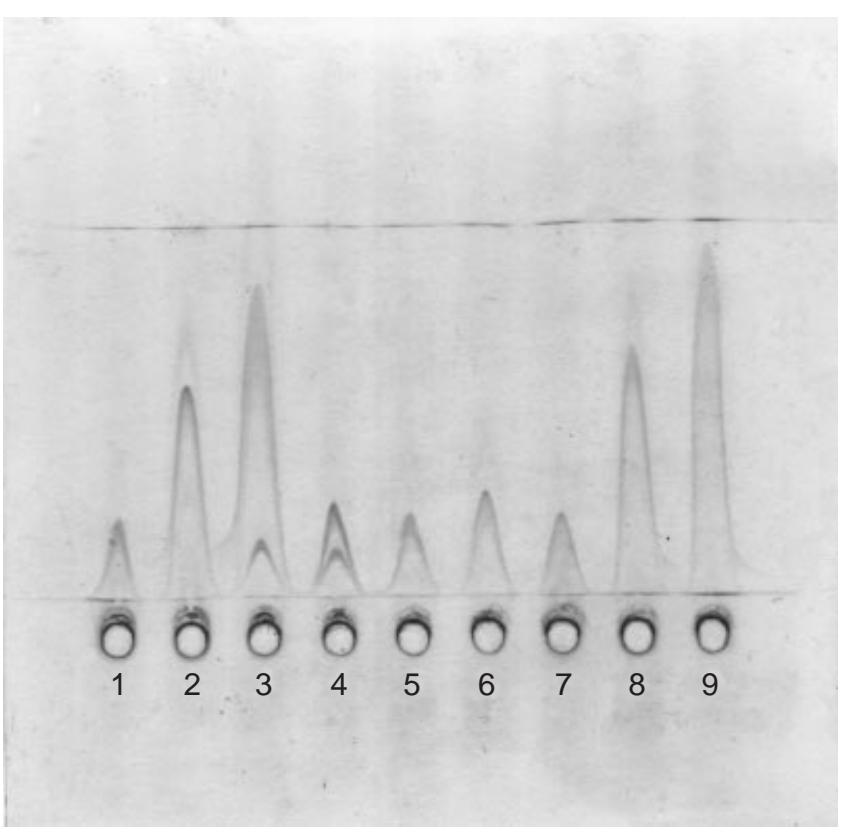

Fig. 4. Coupling activity depends on calcium ions. Lanes 1-3: controls containing a combination of bovine follicular fluid, human stimulation on follicular concentrations of coupling activity and of preformed ITI-hyaluronan complexes. This model accounts for the inter-individual variation between women.

\section{Results}

\section{Occurrence of coupling factor}

Coupling activity was found in follicular fluid (Fig. 1). After mixing of bovine follicular fluid, human serum and hyaluronan, increasing amounts of heavy chain-hyaluronan complexes were formed during $24 \mathrm{~h}$ (Fig. 1; lanes 1-4). In the absence of hyaluronan, no complexes were formed, indicating that hyaluronan was necessary for complex formation (Fig. 1, lanes 5-8). As the antibody used did not precipitate bovine ITI, no genuine hyaluronan-bound ITI was observed (Fig. 1, lane 1). The ITI components released after hyaluronidase treatment showed antigenic nonidentity with bikunin after $24 \mathrm{~h}$ of incubation (Fig. 2, lane

serum and hyaluronan incubated for 0, 2 and 4 h; lanes 4-6: as lanes 1-3 with the addition of Mg-EGTA; lanes 7-9: as lanes 1-3 with addition of Ca-EGTA. 
Table 2. Coupling activity and preformed heavy chain-hyaluronan complexes in follicular fluids obtained from women with different hormone status

\begin{tabular}{|c|c|c|c|c|c|c|}
\hline Hormone status & $\begin{array}{l}\text { Number of } \\
\text { women }\end{array}$ & $\begin{array}{l}\text { Number of } \\
\text { follicles }\end{array}$ & $\begin{array}{l}\text { Coupling activity ab } \\
\qquad\left(\mathrm{m} \mathrm{I} \mathrm{I}^{-1} \mathrm{~h}^{-1}\right)\end{array}$ & $\begin{array}{c}\text { Oestradiol } \\
\mu_{\mathrm{mol} \mathrm{I}}^{-1}\end{array}$ & $\begin{array}{l}\text { Progesterone } \\
\quad \mu \mathrm{mol} \mathrm{I}^{-1}\end{array}$ & $\begin{array}{l}\text { Preformed heavy } \\
\text { chain-hyaluronan } \\
\text { complexes }^{\text {b }} \\
\left(\mathrm{mU} \mathrm{l}^{-1}\right)\end{array}$ \\
\hline $\begin{array}{l}\text { Group } 1 \\
\text { Women stimulated } \\
\text { with exogenous } \\
\text { FSH before the } \\
\text { LH surge }\end{array}$ & 3 & 12 & $0.2(0.4)$ & $16.6(2.4)$ & $12.1(2.4)$ & $34(5.4)^{\mathrm{c}}$ \\
\hline $\begin{array}{l}\text { Group } 2 \\
\text { Women stimulated } \\
\text { with exogenous } \\
\text { FSH and hCG }\end{array}$ & 9 & 18 & $4.3(0.7)$ & $2.1(0.2)$ & $31.0(2.6)$ & $87(7.6)$ \\
\hline $\begin{array}{l}\text { Group } 3 \\
\text { Normal women } \\
\text { after LH surge }\end{array}$ & 11 & 11 & $3.0(0.7)$ & $5.6(0.9)$ & $39.8(3.7)$ & $84(9.4)$ \\
\hline $\begin{array}{l}\text { Group } 4 \\
\quad \text { Normal FSH } \\
\text { plus hCG }\end{array}$ & 9 & 9 & $6.3(1.0)$ & $6.2(0.6)$ & $43.4(2.6)$ & $91(5.6)$ \\
\hline
\end{tabular}

aTested by a random effect-multi level model; concentrations in group 1 were significantly lower than in groups $2-4(P=0.0001)$, and concentrations in group 4 were significantly higher than in groups $1-3(P=0.0025)$.

bMean follicular values. The values in parentheses are the SEM.

concentrations in group 1 were significantly lower than in groups $2-4(P<0.00005)$.

3), whereas the released ITI components that had only been incubated for a short period or for $3 \mathrm{~h}$ gave a small deviation of the bikunin line, indicating that bikunin is present in the early formed complexes (Fig. 2, lanes 1 and 2). As the stable end product contains essentially no bikunin it is referred to as heavy chains.

Various mixtures of follicular fluid, hyaluronan and purified ITI or serum were tested to examine further the components necessary for complex formation. No coupling activity was detected by single incubation of each of hyaluronan, serum, ITI or follicular fluid (human as well as bovine). Furthermore, no formation of heavy chainhyaluronan complexes took place after mixing serum (including ITI) and hyaluronan alone (Table 1, Expt 1). This finding was verified with normal sera from three males and three women obtained at the time of ovulation. Formation of significant amounts of new heavy chain-hyaluronan complexes occurred only when ITI, hyaluronan and components of follicular fluid were present together (Table 1, Expts 5-7). The formation was slow and took place within $24 \mathrm{~h}$. Extension of the incubation period to $48 \mathrm{~h}$ resulted in almost no further increase in heavy chain-hyaluronan complex formation. It was seen that human follicular fluid contained in vivo formed hyaluronan-bound ITI (Table 1, Expts 3-6, $0 \mathrm{~h}$ ). As the antibodies used did not precipitate bovine ITI, the small rocket was assumed to be due to complexes formed within minutes before and after freezing of the assay mixture (Table 1, Expt 7,0 h).

\section{Integrity of ITI}

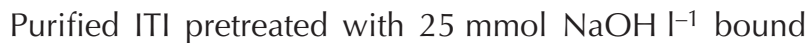
immediately to hyaluronan in the presence of bovine follicular fluid (Table 1, Expt 9 compared with Expt 5). Similar results were obtained using $\mathrm{NaOH}$-treated serum (Expt 8 compared with Expt 7). The $\mathrm{NaOH}$ treatment is known to detach the heavy chain from the chondroitin sulphate bridge of ITI. When $\mathrm{NaOH}$-treated ITI was incubated with hyaluronan alone, no coupling took place.

\section{Evidence for a protein component}

After tryptic digestion of bovine follicular fluid, the coupling activity almost disappeared (Table 1, Expt 10), that is, no increase in rocket height was observed. This effect was blocked by addition of a trypsin inhibitor (SBTI). Heating for $15 \mathrm{~min}$ at $60^{\circ} \mathrm{C}$ reduced the coupling activity of bovine follicular fluid to about $20 \%$ and heating for $15 \mathrm{~min}$ at $75^{\circ} \mathrm{C}$ reduced coupling activity to $11 \%$.

The $\mathrm{pH}$ stability of the coupling activity was tested after reducing the $\mathrm{pH}$ for $1 \mathrm{~h}$ in bovine follicular fluid. The coupling activity was not affected at $\mathrm{pH} 4.0$, but at $\mathrm{pH} 3.0$ the activity was reduced to $50 \%$, and at $\mathrm{pH} 2.0$ to $17.0 \%$. 


\section{Inhibitors}

The effect of various proteinase inhibitors was tested on the ITI coupling reaction.

The two serine proteinase inhibitors PMSF $\left(1 \mathrm{mmol} \mathrm{I}^{-1}\right)$ and benzamidine $\left(25 \mathrm{mmol} \mathrm{I}^{-1}\right)$, the plasmin inhibitor EACA $\left(10 \mathrm{mmol}^{-1}\right)$, the cysteine proteinase inhibitor $p$-chloromercuribenzoate $\left(1 \mathrm{mmol} \mathrm{I}^{-1}\right)$ and the metalloproteinase inhibitor 1,10-phenanthroline $\left(1 \mathrm{mmol} \mathrm{I}^{-1}\right)$ were all unable to inhibit the coupling reaction when tested individually (not shown) or together (Fig. 3, lanes 4-6).

Only EDTA inhibited the coupling reaction, indicating that a di- or tri-valent metal ion was essential (Fig. 3, lanes 7-9). If EDTA was added after the coupling reaction, it had no influence on the preformed ITI-hyaluronan complexes (Fig. 3, lanes 10-12).

The influence of equimolar amounts of $\mathrm{Mg}^{2+}$ and EGTA (Mg-EGTA) or $\mathrm{Ca}^{2+}$ and EGTA (Ca-EGTA) was tested on the coupling reaction to characterize further the necessary ions for coupling activity. Mg-EGTA chelates all di- and trivalent metal ions, but allows free $\mathrm{Mg}^{2+}$ (Holloway and Reilley, 1960). No coupling was observed under these conditions (Fig. 4, lanes 4-6). Calcium saturated with EGTA allows both free $\mathrm{Mg}^{2+}$ and $\mathrm{Ca}^{2+}$, and this was sufficient for coupling to take place (Fig. 4, lanes 7-9). Therefore, $\mathrm{Ca}^{2+}$ must be essential for the coupling reaction, whereas other metal ions such as $\mathrm{Fe}^{3+}, \mathrm{Cu}^{2+}, \mathrm{Zn}^{2+}, \mathrm{Fe}^{2+}$ and $\mathrm{Mg}^{2+}$ should not influence the coupling reaction at physiological concentrations.

\section{Coupling activity and preformed heavy chains-hyaluronan in follicular fluid samples}

The coupling activity and the preformed heavy chainhyaluronan complexes were examined in follicular fluid samples obtained from four groups of women that received different types of ovarian stimulation (Table 2). The group of women (group 1) in which the follicular fluid samples were obtained before initiation of final follicular maturation by either an exogenous bolus of hCG or by an endogenous mid-cycle surge of gonadotrophins showed significantly lower coupling activity and fewer preformed heavy chain-hyaluronan complexes than any of the three other groups. The three groups (2-4) with follicular fluids obtained just before ovulation all showed similar amounts of preformed heavy chain-hyaluronan complexes and were about three times higher than the amounts seen in fluids before the induction of ovulation. The increase in coupling activity was even more pronounced and more than ten times higher after the induction of ovulation (group 1 compared with groups 2-4). The natural menstrual cycle that had an endogenous mid-cycle surge of gonadotrophins (group 3) produced lower amounts of coupling activity than the hCG-stimulated groups, and women with natural menstrual cycles in whom ovulation was induced by a large bolus of hCG (group 4) expressed significantly higher concentrations than the other groups. Concentrations of oestradiol and progesterone confirm that follicular fluid samples were obtained before ovulation was induced (group 1) or close to ovulation (groups 2-4).

\section{Discussion}

The coupling of ITI to hyaluronan is important for normal oocyte development and ovulation (Hess et al., 1999), and is necessary for normal fertility (Sato et al., 2001; Zhuo et al., 2001). However, the mechanisms involved in coupling are mainly unknown. Bikunin is not a part of the ITI-hyaluronan complex (Jessen et al., 1994; Zhuo et al., 2001), but whether the release of bikunin occurs before, during or after the coupling process of heavy chains to hyaluronan is unclear. Furthermore, the nature of the connection has not been fully elucidated (Chen et al., 1996). The covalent binding between heavy chains and hyaluronan in synovial fluid has been described as an ester bond (Zhao et al., 1995), although other types of binding may participate. Possibly, an ion interaction is involved in the primary association between ITI and hyaluronan (Chen et al., 1994). However, in the present study no coupling was observed between ITI and hyaluronan in the presence of physiological salt concentrations, indicating that a possible charge-based interaction is weak. In contrast, stable complexes were formed only in the presence of ITI, hyaluronan and calcium ions in combination with an unknown component of follicular fluid. Zhuo et al. (2001) proposed that an enzymatic factor in mouse serum was necessary for the coupling process. However, in the present study, no activity was found in human serum (male as well as female), indicating that the coupling activity is produced locally by the follicle.

The coupling activity was unaffected by proteinase inhibitors, indicating that a proteolytic cleavage is not involved in the coupling reaction. The coupling activity was found to be sensitive to tryptic digestion, heating and low $\mathrm{pH}$, indicating that the activity may be attached to a protein structure.

The coupling reaction proceeds slowly for many hours. The results from the present study demonstrate that bikunin is present in the early formed complexes between ITI and hyaluronan, indicating that there is a two-step reaction mechanism initiated by the binding of intact ITI followed by a dissociation of bikunin. In agreement with this mechanism, in the present study it was found that heavy chains released from the chondroitin sulphate bridge by treatment of ITI with $25 \mathrm{mmol} \mathrm{NaOH}{ }^{-1}$ bound quickly to hyaluronan, but only in the presence of the coupling activity of follicular fluid. Consequently, the chondroitin sulphate might be a rate-limiting factor in the coupling of heavy chains to hyaluronan and possibly needs to be displaced in agreement with the lack of bikunin in stable complexes. A possible mechanism is a displacement of the chondroitin sulphate bridge by hyaluronan in a trans-ester reaction, in which one or two heavy chains shift from the chondroitin sulphate bridge in ITI to hyaluronan as suggested by Chen et al. (1996) and Zhuo et al. (2001). A 
coupling factor could in this case mediate the reaction by bringing the two reactants (ITI and hyaluronan) in close contact with one another or act as an esterase. As chelation of $\mathrm{Ca}^{2+}$ by EDTA was shown in the present study to have no influence on existing ITI-hyaluronan complexes, $\mathrm{Ca}^{2+}$ might be essential for establishing the contact between the reactants. In support of this contention, a gradual reduction was observed in the formation of heavy chain-hyaluronan complexes when the ionic strength of the reaction media was increased to $0.6 \mathrm{~mol} \mathrm{NaCl} \mathrm{I^{-1 }}$ or higher (data not shown).

The coupling could possibly depend on more proteins working in concert. Some proteins like TSG-6 (Wisniewski et al., 1994) and hyaluronic acid binding protein (Hirashima et al., 1997) have been shown to bind ITI and hyaluronan, and thus may be possible coupling factor candidates. The most likely is TSG- 6 as a 120 kDa complex extracted from mouse COCs consisted of TSG- 6 and either of the heavy chains bound to hyaluronan (Mukhopadhyay et al., 2001). Furthermore, TSG-6 is detected in the extracellular matrix co-localized with ITI and hyaluronan (Carette et al., 2001). The TSG-6-hyaluronan complex contains no bikunin and is resistant to treatment with chondroitinase and hyaluronidase (Mukhopadhaya et al., 2001). This finding is in contrast to complexes formed in vitro between ITI and TSG- 6 that appear to contain the chondroitin sulphate and bikunin plus heavy chain 2 (HC2) (Wisniewski et al., 1994). These findings indicate that a complex between ITI and TSG- 6 is modified further in follicular fluid, perhaps through the action of coupling activity.

TSG-6 gene expression is upregulated in cumulus cells during expansion of mouse COCs in vivo (Fülöp et al., 1997) and in the ovaries 4-8 $\mathrm{h}$ after stimulation with hCG (Yoshioka et al., 2000). The results from human follicular fluid samples in the present study are similar to the TSG-6 expression results, as the mid-cycle surge of gonadotrophins or administration of a large bolus of hCG for ovulation induction also caused accumulation of coupling activity. Compared with before ovulation induction, the coupling activity is more than ten times higher and may therefore reflect an increased expression of TSG-6. It is interesting to note that although deposition of hyaluronan in the extracellular matrix seems to be governed mainly by FSH, coupling activity seems to be induced mainly by LH-hCG. The highest concentration of coupling activity was found in the hCG-stimulated group with normal FSH production. This probably reflects a higher ovulatory stimulus by hCG as compared with the mid-cycle surge of gonadotrophins and demonstrates that LH-hCG is involved in stimulation of synthesis of coupling activity.

As coupling of ITI to hyaluronan is essential for normal fertility in mice (Sato et al., 2001; Zhuo et al., 2001), defects in ITI may play a role in infertility. However, defects in the coupling activity are likely to have similar severe implications for fertility, and isolation and further characterization of the coupling activity is therefore of interest.
In vitro maturation of COCs is becoming increasingly popular to avoid gonadotrophin treatment of women as in conventional IVF treatment. Sufficient amounts of serum and calcium ions need to be present during in vitro conditions to obtain COC expansion of the in vivo unstimulated oocytes. As with calcium, the concentration of ITI in follicular fluid from follicles obtained after stimulation with hCG close to ovulation is almost similar to the concentration in plasma (Ødum et al., 2001). Therefore, it could be of interest to investigate whether addition of follicular fluid from mature follicles obtained close to ovulation would improve COC expansion and subsequent fertilization, and embryo development in connection with in vitro maturation of oocytes.

In conclusion, binding of ITI heavy chains to hyaluronan requires the presence of calcium ions and proteins in the follicular fluid. These appear to be produced locally and stimulated by LH-hCG.

The authors wish to thank B. Avery for donation of follicular fluid, L. Andreasen for skillful technical assistance and S. Kreiner, Department of Biostatistics, University of Copenhagen, for statistical analysis.

\section{References}

Andersen CY (1993) Characteristics of human follicular fluid associated with successful conception after in vitro fertilization Journal of Clinical Endocrinology and Metabolism 77 1227-1234

Andersen CY, Morineau G, Fukuda M, Westergaard LG, Ingerslev HJ, Fiet J and Byskov AG (1999) Assessment of the follicular cortisol:cortisone ratio Human Reproduction 14 1563-1568

Avery B, Hay-Schmidt A, Hyttel P and Greve T (1998) Embryo development, oocyte morphology and kinetics of meiotic maturation in bovine oocytes exposed to 6-dimethylaminopurine prior to in vitro maturation Molecular Reproduction and Development 50 334-344

Axelsen NH and Bock E (1983) Electroimmunoassay (rocket immunoelectrophoresis) Scandinavian Journal of Immunology 17 103-106

Carrette O, Nemade RV, Day AJ, Brickner A and Larsen WJ (2001) TSG-6 is concentrated in the extracellular matrix of mouse cumulus-oocyte complexes through hyaluronan and inter-alpha-inhibitor binding Biology of Reproduction 65 301-308

Chen L, Mao SJ and Larsen WJ (1992) Identification of a factor in fetal bovine serum that stabilizes the cumulus extracellular matrix. A role for a member of the inter-alpha-trypsin inhibitor family Journal of Biological Chemistry 26712 380-12 386

Chen L, Mao SJ, McLean LR, Powers RW and Larsen WJ (1994) Proteins of the inter-alpha-trypsin inhibitor family stabilize the cumulus extracellular matrix through their direct binding with hyaluronic acid Journal of Biological Chemistry 26928 282-28287

Chen L, Zhang H, Powers RW, Russell PT and Larsen WJ (1996) Covalent linkage between proteins of the inter-alpha-inhibitor family and hyaluronic acid is mediated by a factor produced by granulosa cells Journal of Biological Chemistry 271 19 409-19 414

Enghild JJ, Thogersen IB, Pizzo SV and Salvesen G (1989) Analysis of interalpha-trypsin inhibitor and a novel trypsin inhibitor, pre-alpha-trypsin inhibitor, from human plasma. Polypeptide chain stoichiometry and assembly by glycan Journal of Biological Chemistry 26415 975-15981

Eppig JJ (1979) FSH stimulates hyaluronic acid synthesis by oocytecumulus cell complexes from mouse preovulatory follicles Nature $\mathbf{2 8 1}$ 483-484

Fries E and Blom AM (2000) Bikunin - not just a plasma proteinase inhibitor International Journal of Biochemistry and Cell Biology 32 125-137

Fülöp C, Kamath RV, Li Y, Otto JM, Salustri A, Olsen BR, Glant TT and 
Hascall VC (1997) Coding sequence, exon-intron structure and chromosomal localization of murine TNF-stimulated gene 6 that is specifically expressed by expanding cumulus cell-oocyte complexes Gene 202 95-102

Hess KA, Chen L and Larsen WJ (1998) The ovarian blood follicle barrier is both charge- and size-selective in mice Biology of Reproduction $\mathbf{5 8}$ 705-711

Hess KA, Chen L and Larsen WJ (1999) Inter-alpha-inhibitor binding to hyaluronan in the cumulus extracellular matrix is required for optimal ovulation and development of mouse oocytes Biology of Reproduction 61 436-443

Hirashima Y, Kobayashi H, Gotoh J and Terao T (1997) Inter-alpha-trypsin inhibitor is concentrated in the pericellular environment of mouse granulosa cells through hyaluronan-binding European Journal of Obstetrics, Gynecology and Reproductive Biology 73 79-84

Holloway JH and Reilley CN (1960) Metal chelate stability constants of aminopolycarboxylate ligands Analytical Chemistry 32 249-256

Huang L, Yoneda M and Kimata K (1993) A serum-derived hyaluronanassociated protein (SHAP) is the heavy chain of the inter alpha-trypsin inhibitor Journal of Biological Chemistry $26826725-26730$

Jessen TE, Faarvang KL and Ploug M (1988) Carbohydrate as covalent crosslink in human inter-alpha-trypsin inhibitor: a novel plasma protein structure FEBS Letters 230 195-200

Jessen TE, Odum L and Johnsen AH (1994) In vivo binding of human interalpha-trypsin inhibitor free heavy chains to hyaluronic acid Biological Chemistry Hoppe Seyler 375 521-526

Jochum M and Bittner A (1983) Inter-alpha-trypsin inhibitor of human serum: an inhibitor of polymorphonuclear granulocyte elastase Hoppe Seylers Z Physiological Chemistry 364 1709-1715

Lam X, Gieseke C, Knoll M and Talbot P (2000) Assay and importance of adhesive interaction between hamster (Mesocricetus auratus) oocyte-cumulus complexes and the oviductal epithelium Biology of Reproduction 62 579-588

Mukhopadhyay D, Hascall VC, Day AJ, Salustri A and Fulop C (2001) Two distinct populations of tumor necrosis factor-stimulated gene- 6 protein in the extracellular matrix of expanded mouse cumulus cell-oocyte complexes Archives of Biochemistry and Biophysics 394 173-181

Ødum L (1990) Inter-alpha-trypsin inhibitor: a plasma proteinase inhibitor with a unique chemical structure International Journal of Biochemistry 22 925-930

Ødum L and Nielsen HW (1997) Bikunin and alpha 1-microglobulin in human zona pellucida and connective tissue Histochemical Journal 29 199-203
Ødum L, Jessen TE and Andersen CY (2001) Glycosaminoglycan-bound and free inter-alpha-trypsin inhibitor components of follicular fluid Zygote 9 283-288

Powers RW, Chen L, Russell PT and Larsen WJ (1995) Gonadotropinstimulated regulation of blood-follicle barrier is mediated by nitric oxide American Journal of Physiology 269 E290-E298

Salier JP, Rouet P, Raguenez G and Daveau M (1996) The inter-alphainhibitor family: from structure to regulation Biochemical Journal 315 $1-9$

Salustri A, Yanagishita M and Hascall VC (1989) Synthesis and accumulation of hyaluronic acid and proteoglycans in the mouse cumulus cell-oocyte complex during FSH-induced mucification Journal of Biological Chemistry 26413 840-13 847

Sato H, Kajikawa S, Kuroda S et al. (2001) Impaired fertility in female mice lacking urinary trypsin inhibitor Biochemical and Biophysical Research Communications 281 1154-1160

Wisniewski HG, Burgess WH, Oppenheim JD and Vilcek J (1994) TSG-6, an arthritis-associated hyaluronan binding protein, forms a stable complex with the serum protein inter-alpha-inhibitor Biochemistry 33 7423-7429

Wisniewski HG, Hua JC, Poppers DM, Naime D, Vilcek J and Cronstein BN (1996) TNF/IL-1-inducible protein TSG-6 potentiates plasmin inhibition by inter-alpha-inhibitor and exerts a strong anti-inflammatory effect in vivo. Journal of Immunology 156 1609-1615

Yoshioka S, Ochsner S, Russell DL, Ujioka T, Fujii S, Richards JS and Espey LL (2000) Expression of tumor necrosis factor-stimulated gene-6 in the rat ovary in response to an ovulatory dose of gonadotropin Endocrinology 141 4114-4119

Zhao M, Yoneda M, Ohashi Y, Kurono S, Iwata H, Ohnuki Y and Kimata K (1995) Evidence for the covalent binding of SHAP, heavy chains of interalpha-trypsin inhibitor, to hyaluronan Journal of Biological Chemistry $27026657-26663$

Zhuo L, Yoneda M, Zhao M, Yingsung W, Yoshida N, Kitagawa $Y$, Kawamura K, Suzuki T and Kimata K (2001) Defect in SHAPhyaluronan complex causes severe female infertility. A study by inactivation of the bikunin gene in mice Journal of Biological Chemistry $2767693-7696$

Received 10 September 2001.

First decision 23 October 2001.

Final revised manuscript received 9 May 2002.

Accepted 17 May 2002. 